\title{
Simultaneous modulation of the intrinsic and extrinsic pathways by simvastatin in mediating prostate cancer cell apoptosis
}

\author{
Anna Goc ${ }^{1,2 \dagger}$, Samith T Kochuparambil ${ }^{1,2,3 \dagger}$, Belal Al-Husein ${ }^{1,2}$, Ahmad Al-Azayzih ${ }^{1,2}$, Shuaib Mohammad \\ and Payaningal R Somanath ${ }^{1,2,3,4^{*}}$
}

\begin{abstract}
Background: Recent studies suggest the potential benefits of statins as anti-cancer agents. Mechanisms by which statins induce apoptosis in cancer cells are not clear. We previously showed that simvastatin inhibit prostate cancer cell functions and tumor growth. Molecular mechanisms by which simvastatin induce apoptosis in prostate cancer cells is not completely understood.

Methods: Effect of simvastatin on PC3 cell apoptosis was compared with docetaxel using apoptosis, TUNEL and trypan blue viability assays. Protein expression of major candidates of the intrinsic pathway downstream of simvastatin-mediated Akt inactivation was analyzed. Gene arrays and western analysis of PC3 cells and tumor lysates were performed to identify the candidate genes mediating extrinsic apoptosis pathway by simvastatin.

Results: Data indicated that simvastatin inhibited intrinsic cell survival pathway in PC3 cells by enhancing phosphorylation of Bad, reducing the protein expression of $\mathrm{BCl}-2, \mathrm{BCl}-\mathrm{xL}$ and cleaved caspases 9/3. Over-expression of PC3 cells with $\mathrm{BCl}-2$ or DN-caspase 9 did not rescue the simvastatin-induced apoptosis. Simvastatin treatment resulted in increased mRNA and protein expression of molecules such as TNF, Fas-L, Traf1 and cleaved caspase 8, major mediators of intrinsic apoptosis pathway and reduced protein levels of pro-survival genes Lhx4 and Nme5.

Conclusions: Our study provides the first report that simvastatin simultaneously modulates intrinsic and extrinsic pathways in the regulation of prostate cancer cell apoptosis in vitro and in vivo, and render reasonable optimism that statins could become an attractive anti-cancer agent.
\end{abstract}

Keywords: Prostate cancer, Simvastatin, Docetaxel, Apoptosis, Bcl-2, Fas-L

\section{Background}

Statins, the cholesterol lowering drugs, are some of the most commonly prescribed medications. Recently, attention has focused on the development of statins as therapeutic agents for the treatment of solid and hematological cancers [1]. Statins elicit pleiotropic effects on various cell types and differentially modulate cellular functions such as cell migration, proliferation, cell survival and apoptosis in normal and malignant cells [2]. Lipophilicity, dose and duration of the treatment as

\footnotetext{
* Correspondence: sshenoy@georgiahealth.edu

${ }^{\dagger}$ Equal contributors

'Clinical and Experimental Therapeutics, College of Pharmacy, University of Georgia, Augusta, GA, USA

${ }^{2}$ Charlie Norwood VA Medical Center, Augusta, GA, USA

Full list of author information is available at the end of the article
}

well as cell type are all determining factors on the specific effect of a statin on the outcome of a cell function. According to the American Cancer Society, prostate cancer is the most commonly diagnosed cancer and the second leading cause of cancer death in American men. Many recent clinical studies have indicated that use of statins is associated with $>50 \%$ reduction in prostate cancer deaths $[3,4]$. Our previous study showed that simvastatin, a lipophilic statin inhibited multiple prostate cancer cell functions in vitro such as migration, proliferation, cell survival and colony formation as well as tumor growth in a nude mouse xenograft in vivo, mainly via inhibition of Akt pathway [5]. However, exact molecular mechanisms by which statins modulate each of the prostate cancer cell function are not clear.

\section{Ciomed Central}


One of the factors that determine the efficacy of a cancer drug is its ability to inhibit cancer cell survival and induce apoptosis. Meantime, a major concern over the use of anti-cancer drugs for therapy is the side-effects that they can inflict on normal cells. For a very long time, scientists are on the search of anti-cancer agents that specifically target tumor cells with no or minimum effects on normal cells. A very recent study indicates that simvastatin, at doses that we had previously shown to induce apoptosis in prostate cancer cells [5], does not compromise cell survival in normal airway epithelial and fibroblast cells, while inducing apoptosis in breast, hepatocellular and lung carcinoma cells [6]. Although this study provides the necessary assurance that simvastatin may be a potential drug for specifically targeting cancer cells for therapy, the molecular mechanisms by which simvastatin induces apoptosis in cancer cells remains to be determined.

Bcl-2-mediated, mitochondria associated cell survival pathway (intrinsic pathway) is one of the major pathways that are targeted for inducing apoptosis in cancer cells. In addition to this, another major pathway that promotes apoptosis in cancer cells is the death receptor-mediated pathway (extrinsic pathway) [7]. Tumor necrosis factor (TNF), TNF-related apoptosis inducing ligand (TRAIL), Fas-ligand (Fas-L), TNF-related factor-1 and 2 (Traf1/2) etc. are some of the key molecules that belong to the extrinsic pathway or death receptor signaling that are known to be de-regulated in cancers $[8,9]$. While inhibition of Bcl-2-mediated intrinsic pathway leads to the release of cytochrome $\mathrm{c}$ from the mitochondria to the cytosol, resulting in the activation of caspases 9 and 3, death receptor-mediated extrinsic pathway involves caspases 10 and 8 in inducing apoptosis [7]. A pre-requisite for the latter is the formation of a death-inducing signaling complex (DISC) between Fas-assciated death domain (FADD) and pro-caspase 8 [10]. Resulting cleavage of pro-caspase 8 to active cleaved caspase 8 leads to the activation of downstream caspases such as caspase 3 [11].

Until recently, docetaxel-based chemotherapy is the only available treatment option for the androgeninsensitive prostate cancer patients and is shown to modestly improve survival [12], marking the first real advance after the identification of therapeutic castration by Charles Huggins in 1941 [13]. Docetaxel (Taxotere ${ }^{\circledR}$ ) acts via suppression of microtubule assembly and disassembly, microtubule bundling and inhibition of $\mathrm{Bcl}-2$, leading to apoptosis [14]. However, use of docetaxel is associated with a number of serious side-effects due to yet unknown reasons $[15,16]$. According to many reports doses of statins, even 50 times higher than the prescribed doses for the treatment of cardiovascular diseases, did not inflict any serious side-effects or toxicity to liver and kidney in men [17-19]. In the current study, we investigated the various mechanisms by which simvastatin induce apoptosis in prostate cancer cells as compared to the known effects of docetaxel treatment. Our study indicates that simvastatin induces apoptosis in prostate cancer cells in vitro and prostate tumor xenograft in vivo by simultaneously modulating intrinsic and extrinsic apoptotic pathways. These results suggest that simvastatin can be developed as an important drug for the treatment of prostate cancer either alone or in combination with reduced doses of chemotherapeutic drugs such as docetaxel to improve the efficacy and reduce the side-effects.

\section{Methods}

\section{Cell lines, reagents, and antibodies}

Human PC3 and LNCaP cell lines were obtained from ATCC (Manassas, VA) and maintained in DMEM High Glucose (HyClone) with 10\% fetal bovine serum (FBS), 100 units $/ \mathrm{ml}$ penicillin, and $100 \mu \mathrm{g} / \mathrm{ml}$ streptomycin in $5 \% \mathrm{CO}_{2}$ humidified atmosphere at $37^{\circ} \mathrm{C}$. Primary antibodies against $\mathrm{pBad}, \mathrm{Bcl}-2, \mathrm{Bcl}-\mathrm{xL}$, Bim, cleaved caspase 3 , cleaved caspase 9, cleaved caspase 8 , cytocrocme c, Fas-L, survivin and Traf1 were purchased from Cell Signaling (Boston, MA). Primary antibodies anti-Nme 5 was obtained from Abcam (Cambridge, MA/ San Francisco, CA), anti-Trp53inp1 was from R\&D (Minneapolis, MN) and anti- $\beta$-actin was from Sigma (St Louis, MO). Antimouse and anti-rabbit HRP conjugated secondary antibodies were obtained from BioRad (Hercules, CA). Docetaxel and simvastatin were purchased from Sigma (St Louis, MO). Simvastatin was activated in the laboratory using the manufacturer's instructions.

\section{Transfections}

Adenoviral particles for $\mathrm{Bcl}-2$ and DN-Caspase-9 used for the experiments were obtained from Vector BioLabs (Eagleville, PA). For adeno-infections, PC3 cells were grown until reaching $75 \%$ of confluence in 6-well plates. Next, cells were washed with $1 \mathrm{X}$ PBS and $1 \mathrm{ml}$ of DMEM without FBS, supplemented with $10 \mu \mathrm{g}$ of polybrene was added, followed $5 \times 10^{9} \mathrm{PFU} / \mathrm{ml}$ of adeno-Bcl-2 virus and/or $1 \mathrm{X} 10^{10} \mathrm{PFU} / \mathrm{ml}$ of andeno-CMV-caspase9 virus. After 48 hours cells were lysed, protein levels were quantified using DL protein assay (Bio-Rad, Hercules, CA) and subjected to western blot analysis.

\section{Trypan blue viability assessment}

In the trypan blue method, cells were grown to confluence in DMEM with 10\% FBS. The cells were treated with $25 \mu \mathrm{M}$ simvastatin, $10 \mathrm{nM}$ docetaxel, or a combination of both in DMEM. After 24h, cells were collected and re-suspended in PBS with $0.4 \%$ trypan blue solution. Total cells and trypan blue-stained (i.e., nonviable) cells 
were counted, and the percentage of nonviable cells was calculated.

\section{Apoptosis assay}

Cytoplasmic histone-associated DNA fragments were quantified by using the Cell Death Detection ELISA ${ }^{\text {PLUS }}$ kit (Roche Applied Science, Indianapolis, IN) according to the manufacturer's protocol. Briefly, PC3 cells were plated in 96-well plate at a density of either $10^{4}$ cells/ well. After $24 \mathrm{~h}$, the cells were treated with $25 \mu \mathrm{M}$ simvastatin and/or $10 \mathrm{nM}$ docetaxel for $16 \mathrm{~h}$ in DMEM containing 10\% FBS. Control cells received 0.1\% DMSO (vehicle control). Cells were lysed and centrifuged at $200 \mathrm{~g}$ for $10 \mathrm{~min}$, and the collected supernatant was subjected to ELISA. The absorbance was measured at 405 $\mathrm{nm}$ (reference wavelength, $492 \mathrm{~nm}$ ).

\section{Caspase- 9 activity assay}

Caspase- 9 activity assay were performed using CaspaseGlo $^{\circledR} 9$ Assay kit according to the manufacturer's protocol (Promega, Madison, WI). Briefly, PC3 cells were either treated with $25 \mu \mathrm{M}$ simvastatin, $10 \mathrm{nM}$ docetaxel, and a combination of both, or infected with $5 \times 10^{9} \mathrm{PFU} / \mathrm{ml}$ of adeno-Bcl-2 virus and/or $1 \times 10^{10}$ $\mathrm{PFU} / \mathrm{ml}$ of adeno-DN-caspase 9 virus particles. After plating PC3 cells were plated on a 96-well plate at the density of $2.5 \times 10^{4}, 100 \mu \mathrm{l}$ of Caspase-Glo ${ }^{\circledR} 9$ Reagent was added to each well and cells were incubated in room temperature for $2.5 \mathrm{~h}$ followed by the luminescence measurement using an ELISA plate reader. The data are presented as mean \pm S.D.

\section{In vivo nude mouse tumor xenograft model}

All animal procedures listed in this article were performed as per the protocol approved by the Institutional Animal Care and Use Committee at the Charlie Norwood Veterans Affairs Medical Center, Augusta, GA (protocol 09-07-011, dated July 10, 2009). PC3 cells were grown to confluence in 250-ml flasks. Cells were re-suspended in PBS to a concentration of $10^{6} / \mathrm{ml}$. Cell suspension $(1 \mu \mathrm{l})$ was injected subcutaneously in 6- to 8-week-old nude mice (athymic nude mice; Harlan, Indianapolis, IN). The mice were subjected to intraperitoneal injections of simvastatin at a dose of $2 \mathrm{mg} / \mathrm{kg}$ body weight every $12 \mathrm{~h}$ for 2 weeks. The respective controls were injected intraperitoneally with $0.9 \%$ saline every $12 \mathrm{~h}$. Mice were sacrificed on day 14, and tumors were dissected, weighed, and snap frozen using dry ice for further processing to use on western or qRT-PCR.

\section{Terminal deoxynucleotidyl transferase-mediated dUTP nick end labeling (TUNEL) assay}

The TUNEL assay for in situ detection of apoptosis was performed by using the ApopTag ${ }^{\circledR}$ Fluorescein In Situ
Apoptosis detection kit (Millipore, MA) according to the manufacturer's instructions. Cells were plated in 24-well flat bottom plates at a density of $1 \times 10^{5}$ cells/well and treated with $25 \mu \mathrm{M}$ simvastatin, $10 \mathrm{nM}$ docetaxel or a combination of both for $24 \mathrm{~h}$. Following treatments, cells were fixed in $2 \%$ paraformaldehyde at $4^{\circ} \mathrm{C}$ for $30 \mathrm{~min}$. Fixed cells were then permeabilized in $0.1 \%$ Triton X-100 and labeled with fluorescein 12-dUTP using terminal deoxynucleotidyl transferase. Nuclei were counterstained with DAPI. Frozen nude mouse prostate tumor (PC3) xenograft sections were also processed accordingly. Cells/tissue sections were analyzed for apoptotic cells with localized green fluorescence using an inverted fluorescence microscope (Zeiss Axiovert100M, Carl Zeiss, Germany).

\section{QReal-time PCR arrays}

PC3 cells were grown until reaching $75 \%$ of confluence in 6-well plates and subjected to RNA isolation, followed cDNA synthesis and qPCR quantification. Briefly, cells were lysed and RNA was isolated according to manufacturer's protocol using RNAese Mini Plus Kit (Qiagen, Valencia, CA). Next, $25 \mu \mathrm{l}$ of cDNA was produced by $\mathrm{RT}^{2}$ First Strand Kit (SABioscience, Frederick, MD), mixed with qPCR SyberGreen master mix and loaded into Human Apoptosis $\mathrm{RT}^{2}$ Profiler PCR Array plate (SABiosciences, Frederick, MD). Reading was completed in Eppendorf Mastercycler realplex 2 instrument.

\section{Western blot analysis}

PC3 cells were cultured in 6-well plates to reach a monolayer. At that point, the cells were treated with 25 $\mu \mathrm{M}$ simvastatin and/or $10 \mathrm{nM}$ docetaxel in DMEM supplemented with $10 \%$ FBS. Control cells received $0.1 \%$ of DMSO. Whole cell lysates were prepared using lysis buffer $[50 \mathrm{mM}$ Tris- $\mathrm{HCl} \quad(\mathrm{pH}=7.4), 1 \%$ TritonX-100, $150 \mathrm{mM} \mathrm{NaCl}, 1 \mathrm{mM}$ EDTA, 2mM $\mathrm{Na}_{3} \mathrm{VO}_{4}$, and $1 \mathrm{X}$ Complete protease inhibitors (Roche Applied Science, Indianapolis, IN)]. Tumors isolated from mice with C53BL/6 background treated with $2 \mathrm{mg} / \mathrm{kg}$ simvastatin for 11 days, were first snap frozen in liquid nitrogen and then pulverized with mortar and piston. Next, tissues lysates were prepared using lysis buffer. The protein concentration was measured by the DL protein assay (Bio-Rad, Hercules, CA). $60 \mu \mathrm{g} / \mu \mathrm{l}$ of protein was subjected to western blot analysis according to standard Laemmli's method.

\section{Statistical analysis}

Mean activities were calculated from 3-5 independent experiments done at least in triplicates. The Student's two-tailed t test was used to determine significant differences between treatment and control values. 


\section{Results}

Simvastatin induces cell death and apoptosis in prostate cancer cells

Since simvastatin inhibited activity of the cell survival kinase Akt [5], we studied whether treatment with simvastatin will compromise cell survival and induce apoptosis in prostate cancer ( $\mathrm{PC} 3$ and $\mathrm{LNCaP}$ ) cells. A trypan-blue dye based study indicated that treatment with $25 \mu \mathrm{M}$ simvastatin induced $>2$-fold increase in PC3 cell death in $24 \mathrm{~h}$, compared to saline treated controls $(p<0.001)$ (Figure 1A). The effect of simvastatin on PC3 cell death was higher than the effect of $10 \mathrm{nM}$ docetaxel, a currently approved drug for prostate cancer therapy. Interestingly, a combination of simvastatin and docetaxel further enhanced PC3 cell death by another fold, compared to simvastatin treated cells $(p<0.01)$ and 3 -fold higher compared to saline treated controls $(p<0.001)$ (Figure 1A). We next performed apoptosis assay using a method that measures the cytoplasmic histone-associated DNA fragments. Our data confirmed that both simvastatin
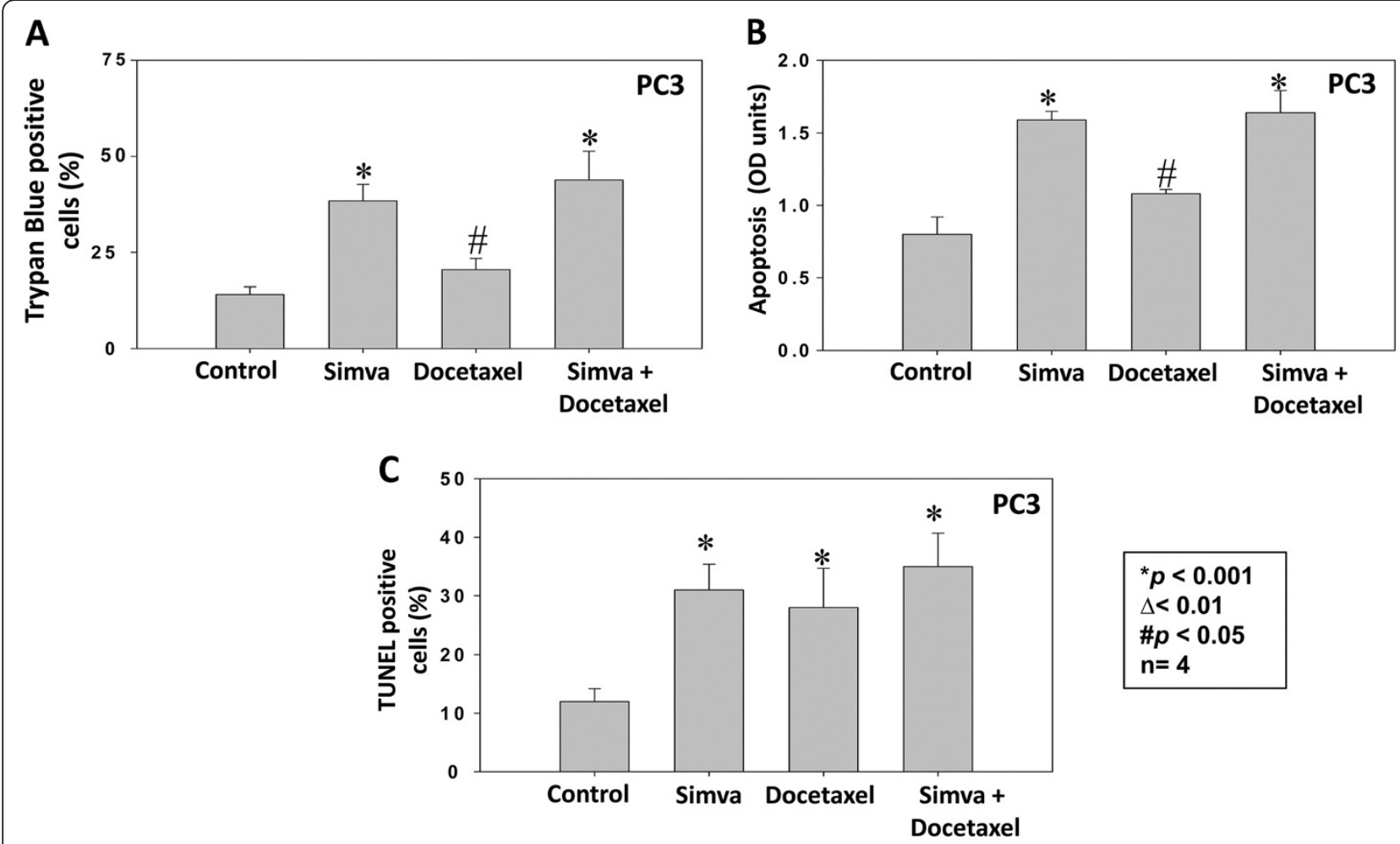

${ }^{*} p<0.001$

$\Delta<0.01$

$\# p<0.05$

$n=4$

D

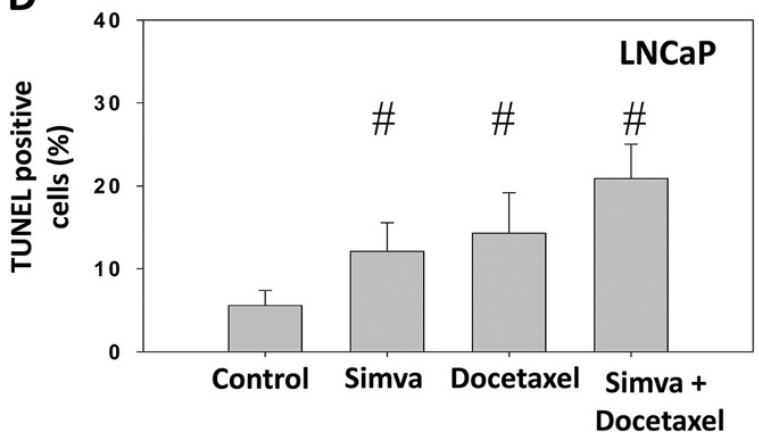

$\mathbf{E}$

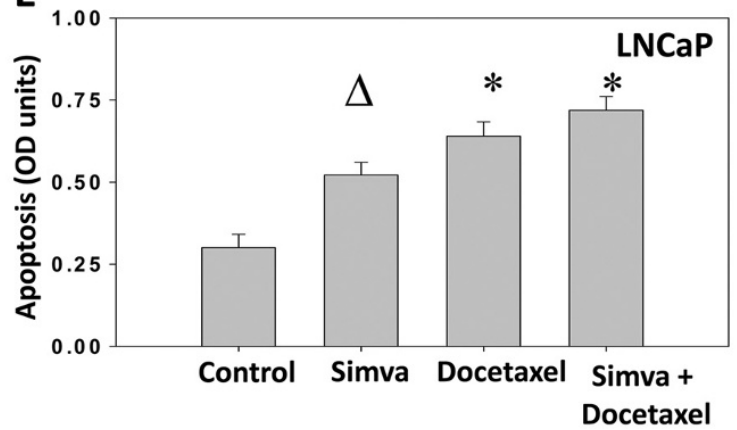

Figure 1 Simvastatin induces cell death and apoptosis in prostate cancer cells. (A) Bar graph showing trypan blue positive PC3 cells treated with control saline, simvastatin, docetaxel or a combination of simvastatin and docetaxel for $12 \mathrm{~h}$. (B) Bar graph showing apoptosis in PC3 cells treated with control saline, simvastatin, docetaxel or a combination of simvastatin and docetaxel for $24 \mathrm{~h}$ as measured calorimetrically. (C) Bar graph showing quantification of TUNEL positive PC3 cells treated with control saline, simvastatin, docetaxel or a combination of simvastatin and docetaxel for 24 h. (D) Bar graph showing quantification of TUNEL positive LNCaP cells treated with control saline, simvastatin, docetaxel or a combination of simvastatin and docetaxel for $24 \mathrm{~h}$. (B) Bar graph showing apoptosis in LNCaP cells treated with control saline, simvastatin, docetaxel or a combination of simvastatin and docetaxel for $24 \mathrm{~h}$. The data are presented as mean \pm SD ( $\mathrm{n}=4$ of quadruplicate experiments). 
and docetaxel significantly induced apoptosis in PC3 cells $(p<0.001$ and $p<0.05$, respectively) (Figure 1B). However, although a trend was noted, the combined effect of simvastatin and docetaxel on the apoptosis of PC3 cells was not observed. In order to further confirm our data, we performed TUNEL assay to assess DNA fragmentation as a late event in the process of apoptosis in PC3 cells. Our TUNEL staining data further confirmed that while simvastatin and docetaxel independently induced apoptosis in PC3 cells $(p<0.001$ and $p<0.05$, respectively), a combination of these drugs exhibited a modest increase in apoptosis compared to each of these drugs alone (Figure $1 \mathrm{C}$ ). We went on to determine whether the effects of simvastatin on apoptosis are also applicable to androgen-responsive LNCaP cells. Our data indicated that confirmed that both simvastatin and docetaxel induced apoptosis in LNCaP cells as evidenced from the TUNEL staining $(p<0.05)$ and $(p<0.01$ and $p<0.001$, respectively) apoptosis assays (Figure 1D and E). Overall, our study demonstrates that simvastatin induces apoptosis in prostate cancer cells.

\section{Simvastatin inhibits $\mathrm{Bcl}-2-$ mediated intrinsic pathway in prostate cancer cells}

Akt is known to modulate Bcl-2-mediated cell survival pathway via phosphorylation of Bcl-2-associated death promoter (Bad). We determined whether simvastatin treatment inhibited Bcl-2-mediated cell survival pathway in prostate cancer cells. Our data indicated that treatment with simvastatin significantly impaired phosphorylation of $\mathrm{Bad}(p<0.05)$, decreased protein expression of $\mathrm{Bcl}-2$ and $\mathrm{Bcl}-\mathrm{xL}(p<0.01$ and $p<0.05$, respectively) as well as increased protein levels of $\operatorname{BimL} / \operatorname{BimS}(p<0.01)$, cleaved caspase 9 and cleaved caspase $3 \quad(p<0.001)$ (Figures $2 \mathrm{~A}$ and $\mathrm{B}$ ). These effects were similar to the treatment of prostate cancer cells with docetaxel. Eventhough a synergistic effect on the protein expression of Bcl-2 and Bcl-xL was seen in prostate cancer cells with combined treatment of simvastatin and docetaxel, a net significant additive effect on the final products of intrinsic pathway such as cleaved caspase 3 and cleaved caspase 9 was not observed (Figure 2A and B). Together, our results indicate that inhibition of $\mathrm{Bcl}-2$ dependent intrinsic pathway is involved in the simvastatin-mediated effects of PC3 cells.

\section{Simvastatin induces apoptosis in prostate tumor} xenografts via inhibition of intrinsic cell survival pathway We next determined whether simvastatin treatment has any effect on prostate tumor cell survival in vivo. In order to do this, frozen sections of PC3 tumor xenografts from athymic nude mice were subjected to TUNEL assay. Our data indicated that treatment with simvastatin in nude mice $(2 \mathrm{mg} / \mathrm{kg}$ body weight/12 hours, intra-peritoneally) significantly enhanced apoptosis in tumors compared to saline treated controls by $>2$-fold $(p<0.05)$ (Figure $3 \mathrm{~A}$ and $\mathrm{B})$. Western analysis of the tumor lysates indicated that, similar to prostate cancer cells in vitro, treatment with simvastatin significantly impaired phosphorylation of $\operatorname{Bad}(p<0.01)$, decreased protein levels of $\mathrm{Bcl}-2$ and $\mathrm{Bcl}-\mathrm{xL}(p<0.01$ and $p<0.001$, respectively), increased release of cytochrome $\mathrm{C}$ from the mitochondria to cytosol $(p<0.05)$ as well as increased protein expressions of BimL/BimS, cleaved caspase 9 and cleaved caspase $3(p<0.05)$, compared to saline treated controls (Figures $4 \mathrm{~A}$ and $\mathrm{B}$ ).

\section{Prostate cancer cells over-expressing Bcl-2 and/or DN- Caspase 9 are not resistant to simvastatin induced apoptosis}

We first determined the effect of simvastatin and docetaxel on caspase 9 enzymatic activity in PC3 cells. Our data show that both simvastatin and docetaxel significantly induced caspase-9 activity in PC3 cells $(p<0.05)$ with a combined effect when simvastatin and docetaxel are used together $(p<0.01)$ (Figure 5A). To determine whether Bcl-2-mediated intrinsic cell survival pathway is the solely affected pathway in prostate cancer cells, we performed rescue experiments by treating PC3 cells over expressing either $\mathrm{Bcl}-2$ or DN-caspase 9 (cleavage resistant) or a combination of both, along with control cells over expressing plasmid vectors. Changes in enzymatic activity of caspase 9 were also confirned with Bcl-2 and DN-caspase 9 plasmid expression in PC3 cells (Figure 5B). Our data indicated that over-expression with Bcl-2, but not caspase-9, enhanced cell survival in PC3 cells $(p<0.001)$ (Figure 5 C and D) as measured by the ELISA-based apoptosis assay kit. However, these cells were not resistant to treatment with simvastatin. No significant inhibition of simvastatin-induced apoptosis was observed by over-expressing PC3 cells with Bcl-2, DN-caspase 9 or a combination of both, compared to vector only expressing controls (Figure $5 \mathrm{C}$ and D). Our data indicate that pathways in addition to intrinsic pathway are involved in simvastatin-induced apoptosis in PC3 cells.

\section{Simvastatin modulates expression of genes involved in the death receptor-mediated apoptotic pathway in prostate cancer cells}

Since over-expression of PC3 cells with Bcl-2 and/or DN-caspase 9 did not rescue from simvastatin-induced apoptosis, we hypothesized that pathways other than intrinsic cell survival pathway may also be inhibited by simvastatin. To study this, we performed Real-Time qPCR-based gene arrays specific for genes involved in the regulation of cell survival and apoptosis. From our gene array analysis, we identified several candidate genes 

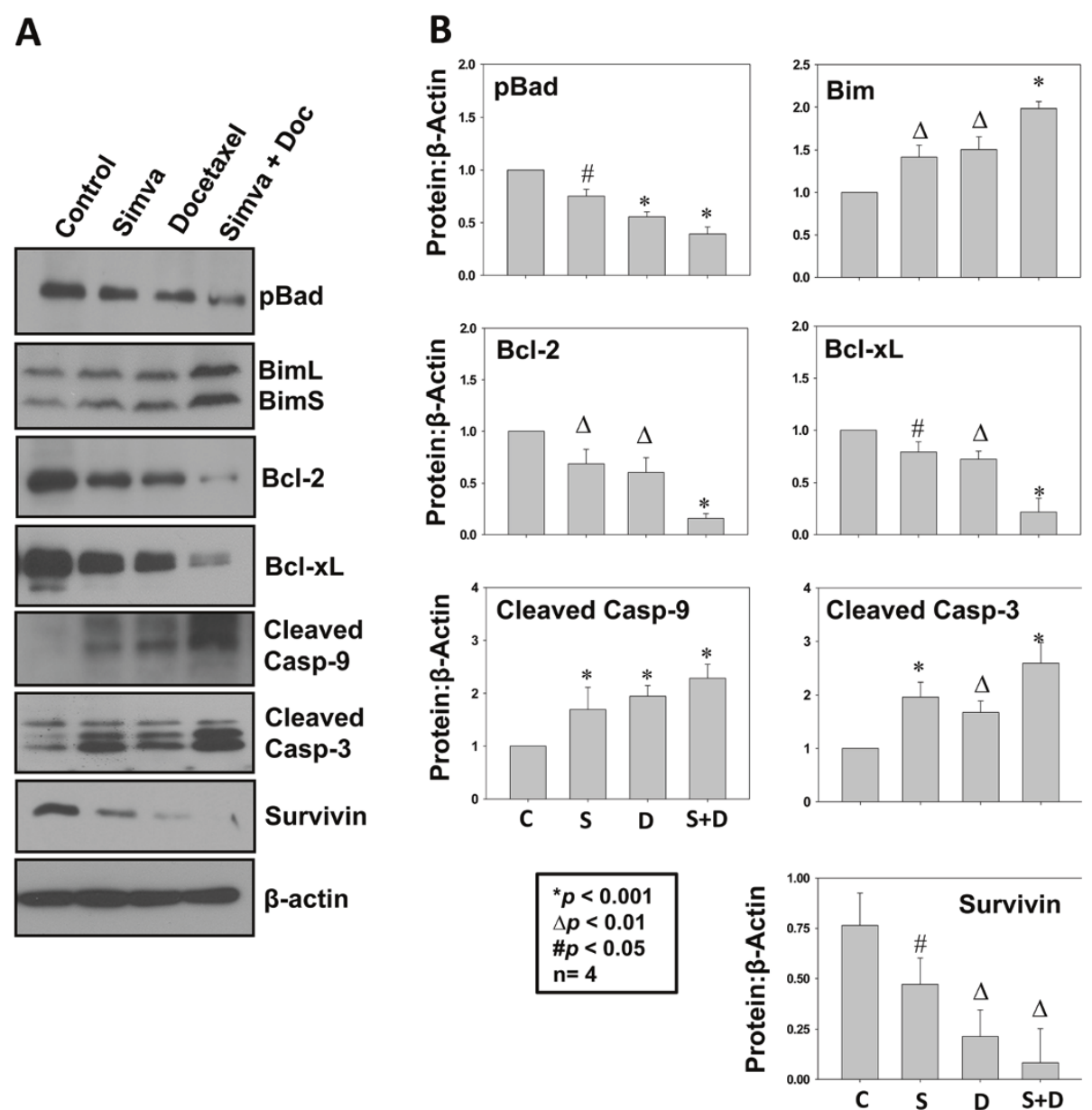

Figure 2 Simvastatin inhibits Bcl-2- and Bcl-xL-mediated cell survival pathway in prostate cancer cells. (A) Western blots showing reduced phosphorylation of Bad, reduced protein expression of $\mathrm{BCl}-2$ and $\mathrm{BCl}-\mathrm{xL}$ as well as increased protein expression of BimL/BimS, cleaved caspase 9 and cleaved caspase 3 after $24 \mathrm{~h}$ treatment with simvastatin, docetaxel or a combination of both, compared to saline treated control (B) Bar graph showing quantification of the above data by densitometry analysis normalized to $\beta$-actin. The data are presented as mean \pm SD ( $n=4$ of quadruplicate experiments).

A

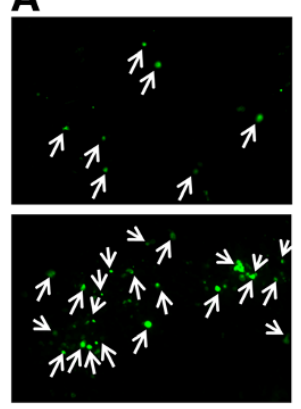

B

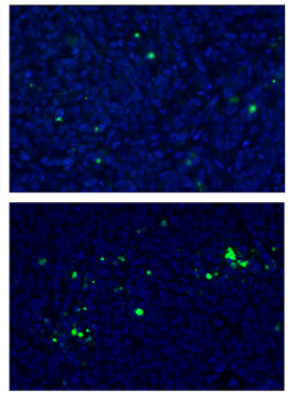

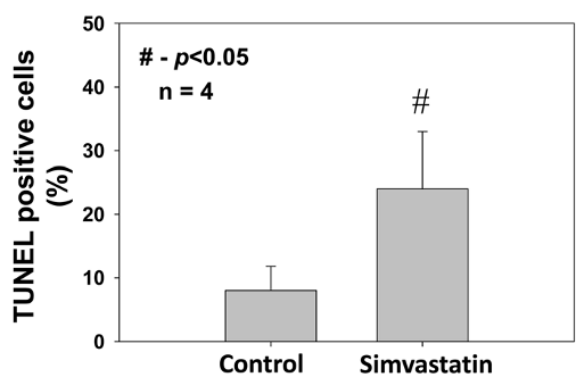

Figure 3 Simvastatin induces cell death and apoptosis in prostate tumor xenografts. (A) Pictures showing TUNEL staining of PC3 cell nude mice tumor xenogafts treated with control saline or simvastatin for 14 days. (B) Bar graph showing quantification of the TUNEL positive PC3 cells in tumor xenogafts treated with control saline or simvastatin for 14 days. The data are presented as mean \pm SD ( $n=4$ of quadruplicate experiments). 


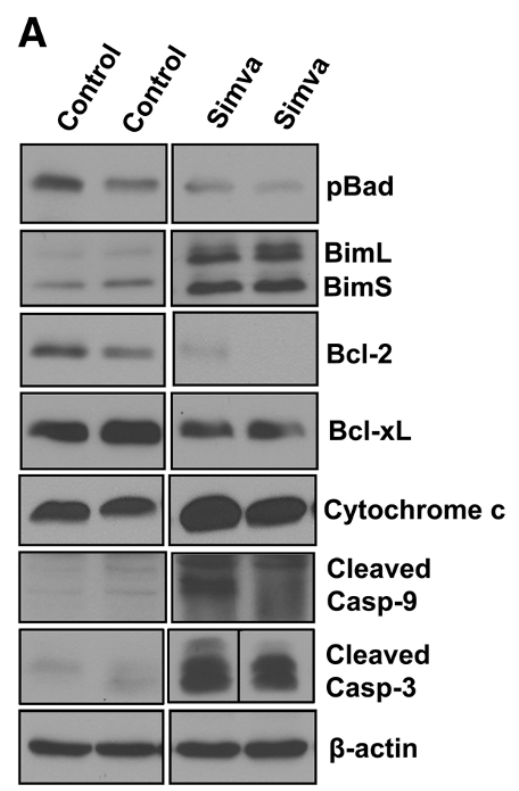

B

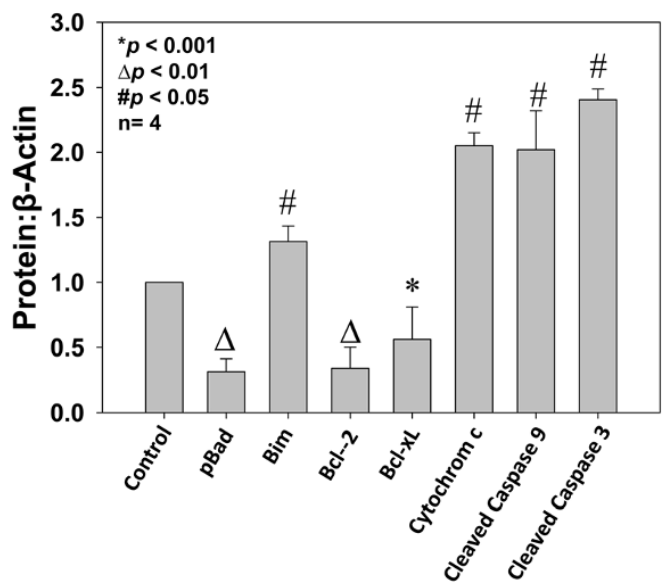

Figure 4 Simvastatin induces apoptosis in prostate tumor cells in vivo via inhibition of intrinsic cell survival pathway. (A) Western blots showing reduced phosphorylation of Bad, reduced protein expression of $\mathrm{BCl}-2$ and $\mathrm{BCl}-\mathrm{xL}$, increased release of cytochrome-c from the mitochondria as well as increased protein expression of BimL/BimS, cleaved caspase 9 and cleaved caspase 3 with 14 day simvastatin treatment, compared to saline control in PC3 cell nude mice tumor xenogafts (B) Bar graph showing quantification of the above data by densitometry analysis normalized to $\beta$-actin. The data are presented as mean $\pm S D$ ( $n=4$ of quadruplicate experiments).

that are likely involved in the simvastatin-induced apoptosis in PC3 cells (Table 1). Some of the candidate genes whose expressions were significantly modulated by statin in PC3 cells included Bcl-2, Fas-L, Lhx4, Nme5, Traf1 and Trp53inp1 $(p<0.001)$, many of them involved in the extrinsic death receptor-mediated apoptosis pathway (Figure 6).

Simvastatin, but not docetaxel is involved in the activation of Fas-L mediated extrinsic pathway in prostate cancer cells and tumor xenografts

To investigate whether these genes were regulated by simvastatin in prostate cancer cells at the protein level, we performed western analysis of PC3 cells treated with either saline control or simvastatin. Our data showed that treatment with simvastatin while significantly increased protein expression of pro-apoptotic Fas-L $(p<0.05)$, it inhibited expression of pro-survival protein Nme5 $(p<0.01)$ (Figure 7A and B). Although a trend towards increased protein expression of Traf1 was observed with simvastatin treatment in PC3 cells lysates, this was however not significant (Figure 7B). In any case, treatment with docetaxel did not have any effect on the expression of proteins involved in the extrinsic pathway involving Fas/Fas-L. Interestingly, we did observe some changes in cleaved caspase 8 protein levels with both simvastatin $(p<0.001)$ and docetaxel treatment $(p<0.05)$, suggesting that docetaxel may also be involved in the regulation of extrinsic pathway through a Fas/Fas-L independent mechanism (Figure 7B).

Using Western analysis of the tumor lysates, we next determined whether simvastatin has effect on extrinsic pathway components in PC3 tumor xenografts in vivo. Our data indicated that while protein levels of Fas-L and Traf1 was significantly increased in PC3 tumors treated with simvastatin, compared to saline treated controls $(p<0.05$ and $p<0.001$, respectively), protein expression of Nme5 was significantly reduced $(p<0.05)$ (Figure 8A and $B)$. Further analysis of tumor cell lysates revealed that protein expression of cleaved caspase 8, a molecule involved in the extrinsic pathway downstream of activated caspase 10 was significantly increased in tumor xenografts treated with simvastatin, compared to saline treated controls $(p<0.01)$ (Figure $8 \mathrm{~A}$ and $\mathrm{B})$.

\section{Discussion}

Many recent studies [1], including ours [5] show that statins are beneficial as anti-cancer agents via inhibition of prostate cancer cell functions in vivo such as proliferation, cell survival, cell migration and colony formation etc. In this study, we have shown that treatment of prostate cancer cells with simvastatin in vitro and mice bearing prostate tumor xenograft in vivo significantly induce apoptosis in prostate cancer cells. Simvastatinmediated effects on prostate cancer cell viability and apoptosis was superior to the effects of docetaxel, a currently approved drug for the chemotherapy of prostate 

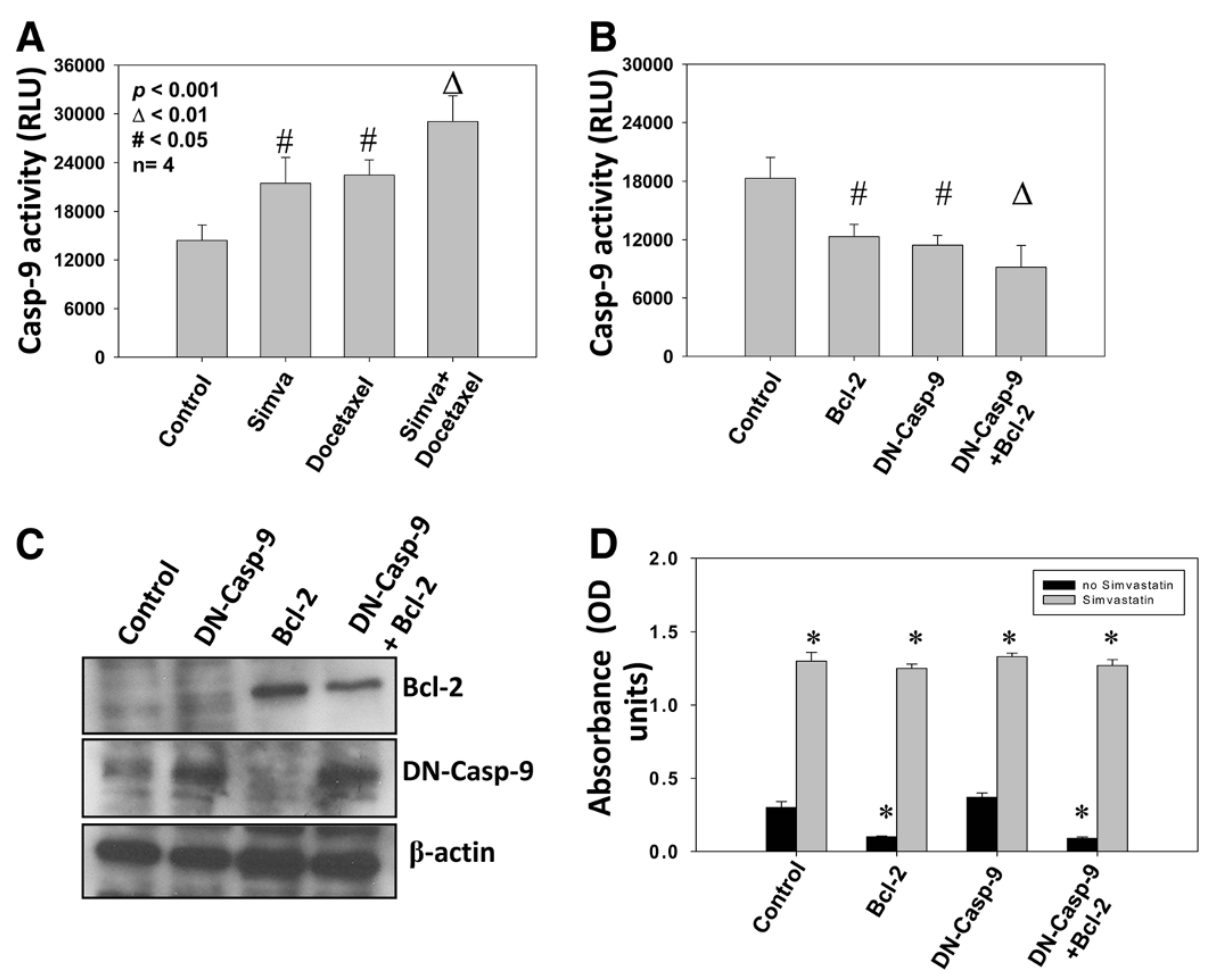

Figure 5 Over-expression with Bcl-2 or DN-caspase 9 does not rescue the simvastatin induces apoptosis in prostate tumor cells. (A) Bar graph showing caspase-9 activity in PC3 cells after $24 \mathrm{~h}$ treatment with simvastatin, docetaxel or a combination of both, compared to saline treated control. (B) Bar graph showing caspase-9 activity in PC3 cells over-expressing BCl-2, DN-caspase 9 and both, compared to vector control in the presence and absence of $24 \mathrm{~h}$ treatment with simvastatin. (C) Western blots showing protein expression of Bcl-2 and caspase-9 in PC3 cells over-expressing BCl-2, DN-caspase 9 and both. (D) Bar graph showing apoptosis of PC3 cells over-expressing BCl-2, DN-caspase 9 and both, compared to vector control in the presence and absence of $24 \mathrm{~h}$ treatment with simvastatin. The data are presented as mean \pm SD ( $n=4$ of quadruplicate experiments).

cancer patients. Although a combined effect on prostate cancer cell viability was observed by treating simvastatin along with docetaxel, this effect was not observed in assays specific for apoptosis such as TUNEL and cytoplasmic histone-associated DNA fragment assays. While Bcl-2-mediated mitochondria-associated intrinsic cell survival pathway was significantly inhibited in PC3 cells and tumor xenografts by simvastatin treatment, overexpression of PC3 cells with $\mathrm{Bcl}-2$ and/or dominant negative caspase 9 did not reverse the simvastatinmediated PC3 cell apoptosis. While simvastatin treatment reduced the expression of phosphorylated-Bad, Bcl-2, Bcl-xL and survivin in PC3 cells, it resulted in increased protein expression of Bim, cleaved caspases 9 and 3, with an increased effect in the presence of docetaxel. Modulation of Bcl-2-pathway with simvastatin was also observed in PC3 tumor lysates. Gene arrays followed by western analysis of PC3 cell and tumor lysates treated with simvastatin identified several genes involved in the extrinsic death-receptor apoptosis pathway modulated by simvastatin, but not with docetaxel, such as tumor necrosis factor (TNF), Fas-L, Traf1 and cleaved caspase 8, along with other genes such as Lhx4, Nme5 and Trp53inp1, which are novel, yet unknown regulators of cell survival and apoptosis in prostate cancer cells. Altogether, our results have demonstrated that simvastatin induces apoptosis in prostate cancer cells via simultaneous modulation of intrinsic and extrinsic pathways (Figure 9).

Because of its 'crossroad' role in multiple essential signaling pathways in cancer cell maintenance, and its enhanced expression and/or activation in multiple cancer cells as compared to normal, Akt kinase is being actively pursued as a novel target for cancer therapy [20-23]. However, since Akt is essential for many normal cell functions [24-26], cell survival in particular, targeting Akt for cancer therapy is a bottle neck due to the serious side-effects associated with it. This asks for novel therapies that can inflict a significant but selective effect on cancer cells in inhibiting pathways like Akt without affecting the normal functioning of extra-tumor tissues. Many recently published reports suggest that statins, at certain higher doses, can be a selective and very efficient drug to treat cancers without inflicting any major sideeffects [17-19]. We previously showed that simvastatin, at a dose $\sim 5$ times higher than the therapeutic dose 
Table 1 Genes modulated by simvastatin in PC3 cells as identified by qRT-PCR arrays

\begin{tabular}{|c|c|c|c|}
\hline GeneBank & Symbol & Description & Change ( $X$ fold) \\
\hline NM_030693 & Atf5 & Activating transcription factor 5 & $2.0 \downarrow$ \\
\hline NM_009741 & $\mathrm{BCl} 2$ & B-cell leukemia/lymphoma 2 & $2.0 \downarrow$ \\
\hline NM_009743 & Bc|2|1/2 & Bcl2-like 1 and 2 & $1.7 \downarrow$ \\
\hline NM_013479 & $\mathrm{BC} 2 \mathrm{2} 10$ & Bcl2-like 10 & $2.0 \downarrow$ \\
\hline NM_008670 & Bircla & Baculoviral IAP repeat-containing 1a & $2.4 \uparrow$ \\
\hline NM_007464 & Birc3 & Baculoviral IAP repeat-containing 3 & $1.6 \uparrow$ \\
\hline NM_009689 & Birc5 & Baculoviral IAP repeat-containing 5 & $3.0 \uparrow$ \\
\hline NM_009807 & Casp1 & Caspase 1 & $2.8 \uparrow$ \\
\hline NM_007702 & Cidea & Cell death-inducing DNA fragmentation factor, alpha subunit-like effector A & $1.6 \uparrow$ \\
\hline NM_010015 & Dad1 & Defender against cell death 1 & $2.5 \downarrow$ \\
\hline NM_010175 & Fadd & Fas (TNFRSF6)-associated via death domain & $2.0 \uparrow$ \\
\hline NM_010177 & Fasl & Fas ligand (TNF superfamily, member 6 ) & $1.9 \uparrow$ \\
\hline NM_010548 & $\| 10$ & Interleukin 10 & $1.6 \uparrow$ \\
\hline NM_010712 & Lhx4 & LIM homeobox protein 4 & $3.3 \downarrow$ \\
\hline NM_080637 & Nme5 & Non-metastatic cells 5, protein expressed in (nucleoside-diphosphate kinase) & $1.8 \downarrow$ \\
\hline NM_030152 & Nol3 & Nucleolar protein 3 (apoptosis repressor with CARD domain) & $1.6 \downarrow$ \\
\hline NM_023258 & Pycard & PYD and CARD domain containing & $2.0 \downarrow$ \\
\hline NM_013693 & Tnf & Tumor necrosis factor & $3.2 \uparrow$ \\
\hline NM_020275 & Tnfrsfiob & Tumor necrosis factor receptor superfamily, member 10b & $1.6 \uparrow$ \\
\hline NM_011611 & $\mathrm{Cd} 40$ & CD40 antigen & $3.5 \uparrow$ \\
\hline NM_009425 & Tnfsf10 & Tumor necrosis factor (ligand) superfamily, member 10 & $1.6 \uparrow$ \\
\hline NM_011617 & Cd70 & CD70 antigen & $3.3 \uparrow$ \\
\hline NM_009421 & Traf1 & Tnf receptor-associated factor 1 & $4.0 \uparrow$ \\
\hline NM_021897 & Trp53inp1 & Transformation related protein 53 inducible nuclear protein 1 & $3.2 \uparrow$ \\
\hline
\end{tabular}

prescribed for the treatment of cardiovascular diseases, significantly inhibited Akt activity in PC3 tumor cells and prostate tumor xenograft growth in vivo [5]. Another recent report indicated that at similar doses, simvastatin

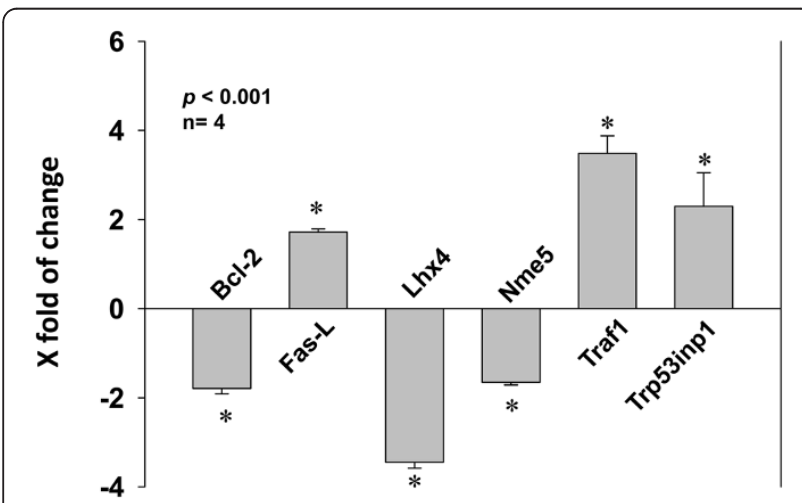

Figure 6 Simvastatin modulates expression of genes in PC3 cells involved in the extrinsic pathway regulating apoptosis. Bar graph showing changes in the mRNA levels of genes such as Bcl-2, Fas-L, Lhx4, Nme5, Traf1 and Trp53inp1 with 24h simvastatin treatment normalized to multiple housekeeping genes. The data are presented as mean $\pm S D$ ( $n=4$ of quadruplicate experiments). induced apoptosis in breast cancer cells, but not in normal airway epithelial cells or fibroblasts [6]. Thus, the ability of simvastatin to selectively inhibit Akt activity and induce apoptosis in prostate cancer cells without affecting the normal cells makes it an attractive candidate for drug re-purposing for cancer therapy.

Many of the effects of simvastatin on prostate cancer cell apoptosis can be credited to its ability to inhibit Akt activity. Akt is known to enhance the intrinsic mitochondriaassociated cell survival pathway in cancer cells via increased phosphorylation of Bad and enhanced expression of Bcl-2 and Bcl-xL [7]. Upon inhibition of Akt by simvastatin in PC3 cells, we saw reduced phosphorylation of Bad, decreased expression of $\mathrm{Bcl}-2$ and $\mathrm{Bcl}-\mathrm{xL}$, associated with increased expression of Bim as well as cleaved caspases 9 and 3. Activated caspase 3 is expected to further cleave PARP in inducing apoptosis [7]. Inhibition of Bcl-2-mediated pathway by statins has also been shown by other labs in multiple cancer types $[6,27,28]$. However, our attempt to rescue the PC3 cells from apoptosis by reconstituting the $\mathrm{Bcl}-2$ pathway by over-expressing PC3 cells with $\mathrm{Bcl}-2$ and/or DN-caspase 9 did not reverse the simvastatin-induced apoptosis. This suggested that 

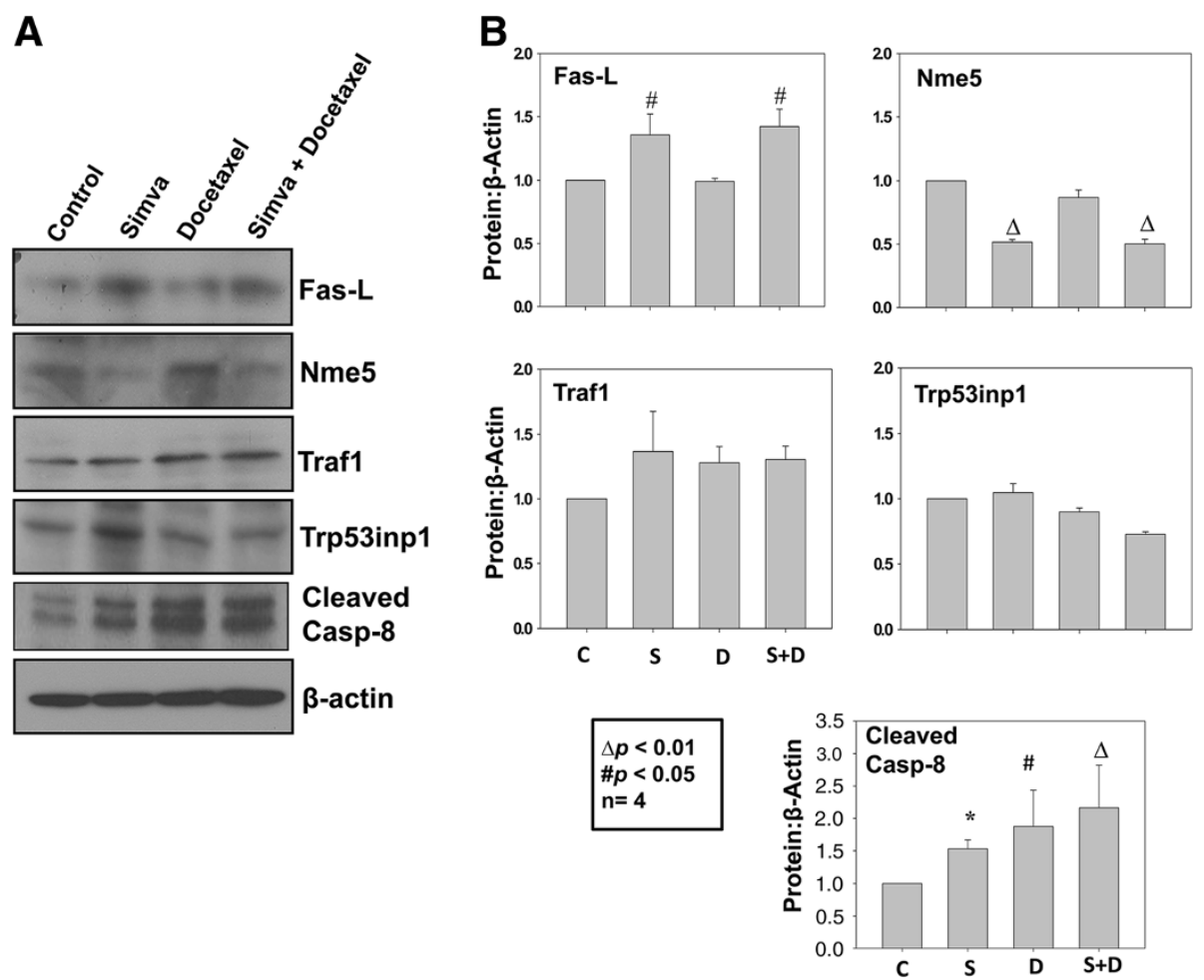

Figure 7 Simvastatin modulates expression of pro-apoptotic extrinsic pathway proteins in PC3 cells. (A) Western blots showing protein expression of Fas-L, Nme5, Traf1, cleaved caspase-8 and Trp53inp1 in PC3 cells treated with simvastatin or docetaxel, compared to control saline treated cells. (B) Bar graph showing quantification of the above data by densitometry analysis normalized to $\beta$-actin. Increase in the protein expression of Traf1, Fas-L and Trp53np1 as well as decreased protein expression of $\mathrm{BCl}-2$ and Nme5 was observed with simvastatin treatment, but not with docetaxel, compared to control. The data are presented as mean \pm SD ( $n=4$ of quadruplicate experiments).

A

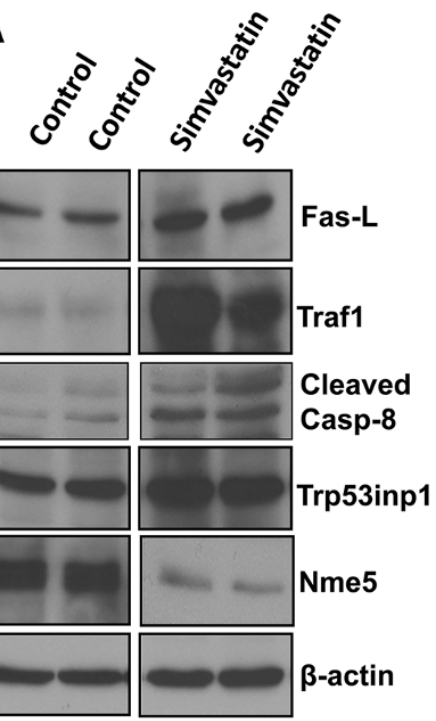

B

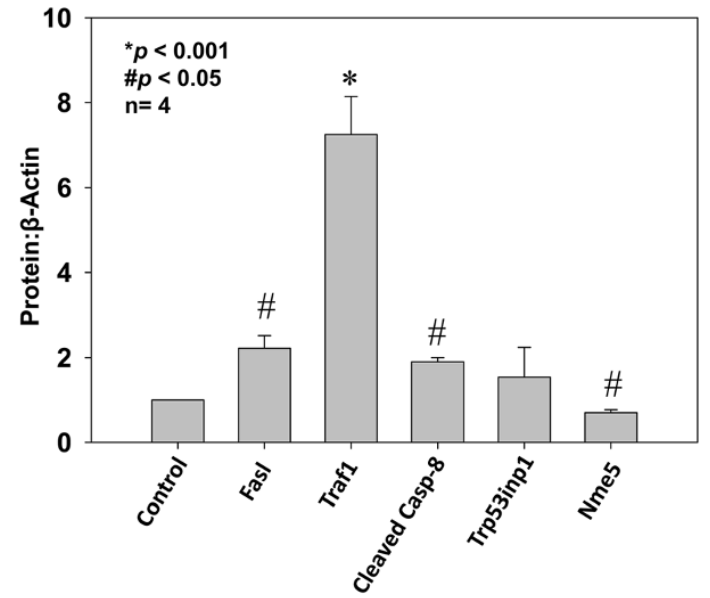

Figure 8 Simvastatin modulates expression of Fas-L, Traf1 and cleaved caspase 8 in prostate tumor xenografts. (A) Western blots showing protein expression of Fas-L, Nme5, Traf1, cleaved caspase 8 and Trp53inp1 in PC3 cell tumor xenografts treated with simvastatin, compared to control saline treated tumors. (B) Bar graph showing quantification of the above data by densitometry analysis normalized to $\beta$-actin. Increased protein expression of Traf1, Fas-L, Trp53np1 and cleaved caspase-8 as well as decreased protein expression of Bcl-2 and Nme5 with simvastatin treatment, but not with docetaxel, compared to control is evident. The data are presented as mean \pm SD ( $n=4$ of quadruplicate experiments). 


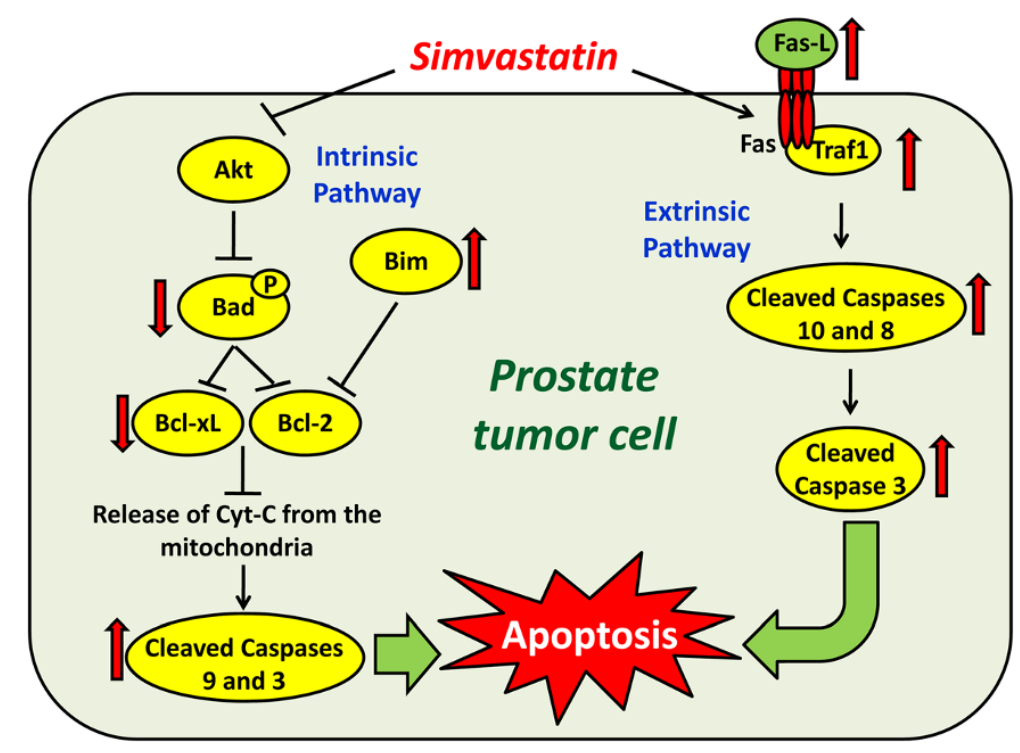

Figure 9 Working hypothesis on the mechanisms by which simvastatin induces apoptosis in prostate cancer cells involving both intrinsic and extrinsic pathways.

pathways other than intrinsic survival pathway are involved in simvastatin-induced apoptosis in prostate cancer cells.

On the other end, gene arrays as well as western analysis of cell and tumor lysates identified a number of novel candidates that are involved in the simvastatininduced apoptosis in prostate cancer cells. One of the pro-survival proteins that were found to be less expressed in simvastatin-treated PC3 cells was survivin, which is also associated with mitochondria-associated cell survival pathway. Survivin is highly expressed in many cancer cells [29], including prostate cancer cells [30,31]. Regulation of survivin expression in multiple experimental models has been linked to increase in Akt activity [32]. In prostate cancer cells, survivin expression has been shown to be regulated by IGF-1 stimulated Akt-mTOR signaling [33], which Is impaired upon simvastatin treatment [5]. A second pro-survival molecule that is significantly less expressed in simvastatin-treated PC3 cells is non-metastatic cells 5 (Nme5). Nme5, also known as the inhibitor of p53-induced apoptosis-beta (IPIA-beta) is known to confer protection from cell death by Bax and alter the cellular levels of several antioxidant enzymes such as Gpx5 [34]. A third molecule that was significantly less expressed in PC3 cells with simvastatin treatment was Lhx4, a molecule abundantly expressed in many cancers $[35,36]$, but exact function is yet to be determined. Other molecules that are deregulated with simvastatin-treatment in PC3 cells include CD70 (TNFRSF7), CD40, caspase-1, Trp53inp1 and TNFRSF10b etc. (Table 1).

Another mechanism by which apoptosis can be triggered in cancer cells is via signaling by death receptor members that belong to the tumor necrosis factor receptor super-family [37]. Among the eight members of the death receptor family, most common are the TNF receptor 1 (TNFR1 or DR1) and Fas (CD95 or DR2) [7]. Our gene array results indicated an increase in TNF and Fas$\mathrm{L}$ in prostate cancer cells, which are ligands for TNFR1 and Fas, respectively, with simvastation treatment. Furthermore, increase in the expression of other molecules associated with the Fas receptor such as Traf1 and Fas (TNFRSF6)-associated via death domain (FADD) leading to activation of caspase-8 was also observed in PC3 cells and/or tumor lysates with simvastatin treatment. In order to induce apoptosis, TNF and Fas-L utilizes two different death receptor signaling complexes. Fas-L-mediated mechanism comprises the death-inducing signaling complexes (DISCs) that are formed at the CD95 or Fas receptor between Fas-assciated death domain (FADD) and procaspases 10 and 8 [10]. Formation of DISC results in the activation of caspases 10 and 8 , which place a central role in the transduction of death signal [10,38]. TNF induces apoptosis via a mechanism different from Fas-induced cell death involving two different signaling complexes [39]. Complex-I is formed at the membrane and comprises TNF, TNFR1, receptor-interacting protein (RIP), TNFR-associated death domain (TRADD), TNFR-associated factors 1 and 2 (Traf-1/2) etc. and acts through a JNK-dependent mechanism. Complex-II, also known as traddosome, consists of FADD and caspase 8, which are absent in complex-I [11]. An increase in the levels of cleaved caspase 8 in the PC3 tumor lysates from simvastation-treated mice indicate that one or both of the Fas-L and TNF-mediated death- 
receptor signaling pathway is involved in simvastatininduced apoptosis in prostate cancer cells.

\section{Conclusions}

In conclusion, our results have demonstrated that treatment with simvastatin induces apoptosis in prostate cancer cells in vitro and tumor xenograft in vivo via simultaneous modulation of mitochondria-associated intrinsic pathway that comprises $\mathrm{Bcl}-2, \mathrm{Bcl}-\mathrm{xL}$ and caspases 9 and 3 as well as Fas-L and TNF-dependent extrinsic death receptor pathway involving caspase-8. Our study reinforces the rationale of selective pharmacologic inhibition of prostate cancer cell survival using statins and suggests re-purposing of lipophilic statins such as simvastatin for prostate cancer therapy in humans. Alternatively, statins may also be used in combination with other cytotoxic agents such as docetaxel to improve the drug efficacy and reduce the side-effects.

\begin{abstract}
Abbreviations
BCl-2: B-Cell lymphoma-2; BCl-xL: B-Cell lymphoma extra-large; DR: Death receptor; DISC: Death-inducing signaling complex;

EDTA: Ethylenediaminetetraacetic acid; FADD: Fas-assciated death domain; Lhx4: LIM homeobox protein-4; Nme5: Non-metastatic cells 5; RIP: Receptorinteracting protein; TNF: Tumor Necrosis factor; TNFRSF: Tumor Necrosis factor receptor superfamily; TRAIL: TNF-related apoptosis inducing ligand; TRADD: TNFR-associated death domain; Traf1/2: TNF-related factor 1 and 2; TUNEL: Terminal deoxynucleotidyl transferase-mediated dUTP nick end labeling.
\end{abstract}

\section{Competing interests}

Authors declare no conflict of interests.

\section{Authors' contributions}

Experiments were conceived and designed by AG, STK and PRS. AG, STK, BA, $A A$ and SM were involved in performing experiments and analyzing the data. Manuscript was written by PRS, AG and STK. All authors revised the manuscript for important intellectual content. All authors read and approved the final manuscript.

\section{Acknowledgements}

We acknowledge the funds provided by the University of Georgia Research Foundation, Wilson Pharmacy Foundation and UGA College of Pharmacy through intramural grants to PRS. Authors also acknowledge partial support from National Institutes of Health grant (R01HL103952) and American Heart Association Scientist Development Grant (0830326N) to PRS.

\section{Author details}

${ }^{1}$ Clinical and Experimental Therapeutics, College of Pharmacy, University of Georgia, Augusta, GA, USA. ${ }^{2}$ Charlie Norwood VA Medical Center, Augusta, GA, USA. ${ }^{3}$ Department of Medicine, Georgia Health Sciences University, Augusta, GA, USA. ${ }^{4}$ Clinical and Experimental Therapeutics, College of Pharmacy, University of Georgia, HM1200 - Georgia Health Sciences University, Augusta, GA 30912, USA.

Received: 14 April 2012 Accepted: 11 September 2012 Published: 14 September 2012

\section{References}

1. Jakobisiak M, Golab J: Statins can modulate effectiveness of antitumor therapeutic modalities. Med Res Rev 2010, 30:102-135.

2. Liao JK, Laufs U: Pleiotropic effects of statins. Annu Rev Pharmacol Toxicol 2005, 45:89-118.

3. Hamilton RJ, Banez LL, Aronson WJ, Terris MK, Platz EA, Kane CJ, Presti JC Jr, Amling CL, Freedland SJ: Statin medication use and the risk of biochemical recurrence after radical prostatectomy: results from the
Shared Equal Access Regional Cancer Hospital (SEARCH) Database. Cancer 2010, 116:3389-3398.

4. Marcella SW, David A, Ohman-Strickland PA, Carson J, Rhoads GG: Statin use and fatal prostate cancer: A matched case-control study. Cancer 2012, 118(16):4046-4052

5. Kochuparambil ST, Al-Husein B, Goc A, Soliman S, Somanath PR: Anticancer efficacy of simvastatin on prostate cancer cells and tumor xenografts is associated with inhibition of Akt and reduced prostate-specific antigen expression. J Pharmacol Exp Ther 2011, 336:496-505.

6. Spampanato C, De Maria S, Sarnataro M, Giordano E, Zanfardino M, Baiano S, Carteni M, Morelli F: Simvastatin inhibits cancer cell growth by inducing apoptosis correlated expression. Int J Oncol 2012, 40:935-941.

7. Fulda S, Debatin KM: 5-Aza-2/-deoxycytidine and IFN-gamma cooperate to sensitize for TRAIL-induced apoptosis by upregulating caspase-8. Oncogene 2006, 25:5125-5133.

8. French LE, Tschopp J: Protein-based therapeutic approaches targeting death receptors. Cell Death Differ 2003, 10:117-123.

9. Wajant H: Death receptors. Essays Biochem 2003, 39:53-71.

10. Peter ME, Krammer PH: The CD95(APO-1/Fas) DISC and beyond. Cell Death Differ 2003, 10:26-35

11. Micheau O, Tschopp J: Induction of TNF receptor I-mediated apoptosis via two sequential signaling complexes. Cell 2003, 114:181-190.

12. Massard C, Fizazi K: Targeting continued androgen receptor signaling in prostate cancer. Clin Cancer Res 2011, 17:3876-3883.

13. Huggins C, Hodges CV: Studies on prostatic cancer: I. The effect of castration, of estrogen and of androgen injection on serum phosphatases in metastatic carcinoma of the prostate. 1941. J Urol 2002 168:9-12.

14. Herbst RS, Khuri FR: Mode of action of docetaxel - a basis for combination with novel anticancer agents. Cancer Treat Rev 2003, 29:407-415.

15. Eckhoff $L$, Nielsen M, Moeller S, Knoop A: TAXTOX - a retrospective study regarding the side effects of docetaxel given as part of the adjuvant treatment to patients with primary breast cancer in Denmark from 2007 to 2009. Acta Oncol 2011, 50:1075-1082

16. Pivot $X$, Schneeweiss A, Verma S, Thomssen C, Passos-Coelho JL, Benedetti G, Ciruelos E, von Moos R, Chang HT, Duenne AA, Miles DW: Efficacy and safety of bevacizumab in combination with docetaxel for the first-line treatment of elderly patients with locally recurrent or metastatic breast cancer: results from AVADO. Eur J Cancer 2011, 47:2387-2395.

17. Thibault A, Samid D, Tompkins AC, Figg WD, Cooper MR, Hohl RJ, Trepel J, Liang B, Patronas N, Venzon DJ, et al: Phase I study of lovastatin, an inhibitor of the mevalonate pathway, in patients with cancer. Clin Cancer Res 1996, 2:483-491.

18. van der Spek E, Bloem AC, van de Donk NW, Bogers LH, van der Griend R, Kramer MH, de Weerdt O, Wittebol S, Lokhorst HM: Dose-finding study of high-dose simvastatin combined with standard chemotherapy in patients with relapsed or refractory myeloma or lymphoma. Haematologica 2006, 91:542-545.

19. Holstein SA, Knapp HR, Clamon GH, Murry DJ, Hohl RJ: Pharmacodynamic effects of high dose lovastatin in subjects with advanced malignancies. Cancer Chemother Pharmacol 2006, 57:155-164.

20. Somanath PR, Vijai J, Kichina JV, Byzova T, Kandel ES: The role of PAK-1 in activation of MAP kinase cascade and oncogenic transformation by Akt. Oncogene 2009, 28:2365-2369.

21. Goc A, Al-Husein B, Kochuparambil ST, Liu J, Heston WW, Somanath PR: PI3 kinase integrates Akt and MAP kinase signaling pathways in the regulation of prostate cancer. Int J Oncol 2011, 38:267-277.

22. Crowell JA, Steele VE, Fay JR: Targeting the AKT protein kinase for cancer chemoprevention. Mol Cancer Ther 2007, 6:2139-2148.

23. Davies MA: Regulation, role, and targeting of Akt in cancer. J Clin Oncol 2011, 29:4715-4717.

24. Chen J, Somanath PR, Razorenova O, Chen WS, Hay N, Bornstein P, Byzova TV: Akt1 regulates pathological angiogenesis, vascular maturation and permeability in vivo. Nat Med 2005, 11:1188-1196.

25. Somanath PR, Kandel ES, Hay N, Byzova TV: Akt1 signaling regulates integrin activation, matrix recognition, and fibronectin assembly. J Biol Chem 2007, 282:22964-22976.

26. Somanath PR, Razorenova OV, Chen J, Byzova TV: Akt1 in endothelial cell and angiogenesis. Cell Cycle 2006, 5:512-518. 
27. Shibata MA, Ito Y, Morimoto J, Otsuki Y: Lovastatin inhibits tumor growth and lung metastasis in mouse mammary carcinoma model: a p53-independent mitochondrial-mediated apoptotic mechanism. Carcinogenesis 2004, 25:1887-1898.

28. Gauthaman K, Manasi N, Bongso A: Statins inhibit the growth of variant human embryonic stem cells and cancer cells in vitro but not normal human embryonic stem cells. Br J Pharmacol 2009, 157:962-973.

29. Fukuda S, Pelus LM: Survivin, a cancer target with an emerging role in normal adult tissues. Mol Cancer Ther 2006, 5:1087-1098.

30. Fornaro M, Plescia J, Chheang S, Tallini G, Zhu YM, King M, Altieri DC, Languino LR: Fibronectin protects prostate cancer cells from tumor necrosis factor-alpha-induced apoptosis via the AKT/survivin pathway. J Biol Chem 2003, 278:50402-50411.

31. Krajewska M, Krajewski S, Banares S, Huang X, Turner B, Bubendorf L, Kallioniemi OP, Shabaik A, Vitiello A, Peehl D, et al: Elevated expression of inhibitor of apoptosis proteins in prostate cancer. Clin Cancer Res 2003, 9:4914-4925.

32. Amaravadi R, Thompson CB: The survival kinases Akt and Pim as potential pharmacological targets. J Clin Invest 2005, 115:2618-2624.

33. Vaira V, Lee CW, Goel HL, Bosari S, Languino LR, Altieri DC: Regulation of survivin expression by IGF-1/mTOR signaling. Oncogene 2007, 26:2678-2684

34. Munier A, Feral C, Milon L, Pinon VP, Gyapay G, Capeau J, Guellaen G, Lacombe ML: A new human nm23 homologue $(\mathrm{nm} 23-\mathrm{H} 5)$ specifically expressed in testis germinal cells. FEBS Lett 1998, 434:289-294.

35. Kawamata N, Sakajiri S, Sugimoto KJ, Isobe Y, Kobayashi H, Oshimi K: A novel chromosomal translocation $\mathrm{t}(1 ; 14)(\mathrm{q} 25 ; \mathrm{q} 32)$ in pre-B acute lymphoblastic leukemia involves the LIM homeodomain protein gene, Lhx4. Oncogene 2002, 21:4983-4991.

36. Hung TM, Hu RH, Ho CM, Chiu YL, Lee JL, Jeng YM, Shih DT, Lee PH: Downregulation of alpha-fetoprotein expression by LHX4: a critical role in hepatocarcinogenesis. Carcinogenesis 2011, 32:1815-1823.

37. Bhardwaj A, Aggarwal BB: Receptor-mediated choreography of life and death. J Clin Immunol 2003, 23:317-332.

38. Sprick MR, Rieser E, Stahl H, Grosse-Wilde A, Weigand MA, Walczak H: Caspase- 10 is recruited to and activated at the native TRAIL and CD95 death-inducing signalling complexes in a FADD-dependent manner but can not functionally substitute caspase-8. EMBO J 2002, 21:4520-4530.

39. Varfolomeev EE, Ashkenazi A: Tumor necrosis factor: an apoptosis JuNKie? Cell 2004, 116:491-497.

doi:10.1186/1471-2407-12-409

Cite this article as: Goc et al:: Simultaneous modulation of the intrinsic and extrinsic pathways by simvastatin in mediating prostate cancer cell apoptosis. BMC Cancer 2012 12:409.

\section{Submit your next manuscript to BioMed Central and take full advantage of:}

- Convenient online submission

- Thorough peer review

- No space constraints or color figure charges

- Immediate publication on acceptance

- Inclusion in PubMed, CAS, Scopus and Google Scholar

- Research which is freely available for redistribution 